\title{
Thermogenic responses in Eurasian Tree Sparrow (Passer montanus) to seasonal acclimatization and temperature-photoperiod acclimation
}

\author{
Lin $\mathrm{Li}^{\dagger}$, Jingru Ge${ }^{\dagger}$, Sangyu Zheng, Lihong Hong, Xini Zhang, Ming Li ${ }^{*}$ and Jinsong Liu*
}

\begin{abstract}
Background: Small birds in temperate habitats must either migrate, or adjust aspects of their morphology, physiology and behavior to cope with seasonal change in temperature and photoperiod. It is, however, difficult to accurately measure how seasonal changes in temperature and photoperiod affect physiological processes such as basal metabolic rate (BMR) and metabolic activity. To address this problem, we collected data in each month of the year on body mass $\left(M_{b}\right)$ and $B M R$, and conducted a series of experiments to determine the effect of temperature and photoperiod on $M_{b}$, BMR and physiological markers of metabolic activity, in the Eurasian Tree Sparrow (Passer montanus).
\end{abstract}

Methods: In one experiment, we measured monthly change in $M_{\mathrm{b}}$ and BMR in a captive group of birds over a year. In another experiment, we examined the effects of acclimating birds to two different temperatures, 10 and $30{ }^{\circ} \mathrm{C}$, and a long and a short photoperiod (16 h light:8 $\mathrm{h}$ dark and $8 \mathrm{~h}$ light: $16 \mathrm{~h}$ dark, respectively) for 4 weeks.

Results: We found that these treatments induced sparrows to adjust their $M_{\mathrm{b}}$ and metabolic rate processes. Acclimation to $30^{\circ} \mathrm{C}$ for 4 weeks significantly decreased sparrows' $M_{b}$, BMR, and energy intake, including both gross energy intake and digestible energy intake, compared to birds acclimated to $10^{\circ} \mathrm{C}$. The dry mass of the liver, kidneys and digestive tract of birds acclimated to $30^{\circ} \mathrm{C}$ also significantly decreased, although their heart and skeletal muscle mass did not change significantly relative to those acclimated to $10^{\circ} \mathrm{C}$. Birds acclimated to $30^{\circ} \mathrm{C}$ also had lower mitochondrial state-4 respiration (S4R) and cytochrome c oxidase (COX) activity in their liver and skeletal muscle, compared to those acclimated to $10^{\circ} \mathrm{C}$. Birds acclimated to the long photoperiod also had lower mitochondrial S4R and COX activity in their liver, compared to those acclimated to the short photoperiod.

Conclusions: These results illustrate the changes in morphology, physiology, and enzyme activity induced by seasonal change in temperature and photoperiod in a small temperate passerine. Both temperature and photoperiod probably have a strong effect on seasonal variation in metabolic heat production in small birds in temperate regions. The effect of temperature is, however, stronger than that of photoperiod.

Keywords: Acclimation, Acclimatization, Basal metabolic rate, Body mass, Eurasian tree sparrow (passer montanus)

*Correspondence: limingjinwen@126.com; ljs@wzu.edu.cn

${ }^{\dagger} \mathrm{Lin} \mathrm{Li}$ and Jingru Ge contributed equally to this work College of Life and Environmental Sciences, Wenzhou University, Wenzhou 325035, China

\section{Background}

Phenotypic flexibility can be defined as reversible, temporary and repeatable, changes organisms in response to changes in the internal or external environment (Piersma and Drent 2003; Starck and Rahmaan 2003; original author(s) and the source, provide a link to the Creative Commons licence, and indicate if changes were made. The images or other third party material in this article are included in the article's Creative Commons licence, unless indicated otherwise in a credit line to the material. If material is not included in the article's Creative Commons licence and your intended use is not permitted by statutory regulation or exceeds the permitted use, you will need to obtain permission directly from the copyright holder. To view a copy of this licence, visit http://creativecommons.org/licenses/by/4.0/. The Creative Commons Public Domain Dedication waiver (http://creativeco mmons.org/publicdomain/zero/1.0/) applies to the data made available in this article, unless otherwise stated in a credit line to the data. 
McKechnie 2008). One well-known example of phenotypic flexibility is the seasonal phenotypes that animals develop in response to seasonal climatic variation (Swanson 2010). In birds, phenotypic flexibility in energy expenditure is an important component of their thermoregulatory response to elevated seasonal energy requirements (Swanson 2010; Zheng et al. 2008a, 2014a). Winter is an energetically demanding period for small birds in temperate zones because thermoregulatory costs typically increase while food quality and availability decrease. Many small birds seasonally adjust their morphology, physiology, and behavior to cope with such seasonal variation in temperature and food (Liknes and Swanson 1996; Zheng et al. 2008a, 2008b; Zhang et al. 2018a). These seasonal metabolic adjustments typically include winter increases in both basal metabolic rate (BMR) and maximum metabolic rate (MMR) (McNab 2009; Swanson 1990, 2010; Zheng et al. 2008a, 2014a). BMR is the rate of energy transformation in a rested, inactive and postabsorptive state in the absence of thermal stress, and is the minimum metabolic rate of animals maintaining normal physiological function (McNab 1997; Zheng et al. 2008a; Swanson 2010; Zhang et al. 2018b). BMR is widely used as an index of energy expenditure by environmental and comparative physiologists (Zheng et al. 2008a; Swanson 2010; Sandoval and David 2012; Zhou et al. 2016; Bushuev et al. 2018).

Temperature and photoperiod are considered the most important environmental factors influencing seasonal thermoregulation in animals, and are thought to drive the evolution of a suite of morphological, physiological and behavioral adaptations (Liknes and Swanson 1996; McKechne and Swanson 2010; Swanson et al. 2014; Zhang et al. 2018a). It has been demonstrated that a bird's BMR, body mass $\left(M_{\mathrm{b}}\right)$ and energy balance are all affected by temperature and photoperiod (McKechnie 2008; McKechnie and Swanson 2010; Swanson et al. 2014; Hu et al. 2017). Cold-acclimated birds often, though not always, exhibit higher BMR than warm acclimated ones (Zhou et al. 2016; Cui et al. 2019). This has been demonstrated in a variety of avian species, such as the Laughing Dove (Streptopelia senegalensis) (McKechnie et al. 2007), the Rufous-collared Sparrow (Zonotrichia capensis) (Maldonado et al. 2009), the Hwamei (Garrulax canorus) (Zhou et al. 2016), the Chinese Bulbul (Pycnonotus sinensis) (Hu et al. 2017) and the Red-billed Leiothrix (Leiothrix lutea) (Cui et al. 2019). Short photoperiods, either alone, or in combination with cold, can also increase metabolic thermogenesis in birds (Saarela and Heldmaier 1987; Hu et al. 2017). Conversely, there is evidence that warmer temperatures and/or long photoperiods decrease
BMR (Williams and Tieleman 2000; Zheng et al. 2013a; Hu et al. 2017; Zhang et al. 2018b).

Birds also show increases in internal organ mass under cold temperatures and/or short photoperiod conditions. It has been hypothesized that such changes are an adaptation to different energy requirements and are related to the increased metabolic activity required for elevated BMR (Williams and Tieleman 2000; Swanson et al. 2014; Hu et al. 2017; Cui et al. 2019). The liver is one of the largest and most metabolically active organs in endotherms. Under basal metabolic conditions, the liver has been shown to contribute $20-25 \%$ of total heat production in animals (Liu and Li 2006; Zheng et al. 2008a; Bai et al. 2016). Skeletal muscle comprises nearly $40 \%$ of $M_{\mathrm{b}}$ and is a primary contributor to thermogenesis (Zhou et al. 2016). Birds also use biochemical adjustments to regulate BMR (McKechnie 2008; Swanson 2010; Peña-Villalobos et al. 2014; Swanson et al. 2017). Changes in catabolic enzyme activity and/or the capacity for metabolic substrate transport can influence the mass-specific metabolic intensities of organs, and thereby metabolic rate (Else et al. 2004; Liknes and Swanson 2011; Zheng et al. 2008a, 2014a). Finally, levels of mitochondrial state-4 respiration (S4R; an indicator of oxidative phosphorylation capacity) and cytochrome c oxidase (COX; a key regulatory enzyme in oxidative phosphorylation) activity are commonly used as enzymatic markers of BMR at the cellular level (Zheng et al. 2008b, 2013b, 2014a; Zhou et al. 2016; Hu et al. 2017; Zhang et al. 2018b).

The Eurasian Tree Sparrow (Passer montanus) is a small granivorous passerine that inhabits vast areas of Europe and Asia (MacKinnon and Phillipps 2000). We chose the Eurasian Tree Sparrow as a study species because they have such a vast geographic range, which includes Zhejiang Province where we are based, and because previous studies of this species (Liu and Li 2006; Liu et al. 2008; Zheng et al. 2008b, 2014b) provide essential background information required for our current research.

Eurasian Tree Sparrows mainly appear to cope with cold temperatures or short photoperiods by increasing their organ mass and respiratory enzyme activity, thereby increasing their BMR (Liu and Li 2006; Liu et al. 2008; Zheng et al. 2008b, 2014b). Whether acclimation to warm temperatures or long photoperiods causes sparrows to decrease their BMR is, however, unknown. This paper describes the results of experiments designed to test the effects of temperature and photoperiod on the $M_{\mathrm{b}}$, BMR, internal organ mass and key aerobic enzyme activity of the Eurasian Tree Sparrow. We hypothesized that Eurasian Tree Sparrows adapt to seasonal changes in temperature and photoperiod by making seasonal adjustments to their $M_{\mathrm{b}}$ and thermogenesis, including decreasing thermogenic capacity and $M_{\mathrm{b}}$ in response to warm 
temperatures or long photoperiods. To test this hypothesis we monitored seasonal changes in $M_{\mathrm{b}}$ and BMR in Eurasian Tree Sparrows and measured the effects of 4 weeks acclimation to different temperature and photoperiods conditions on their BMR, energy budget, organ masses, and physiological and biochemical markers of metabolic activity.

\section{Methods}

\section{Animals and experiments}

This study was carried out in Wenzhou City, Zhejiang Province $\left(27^{\circ} 29 \mathrm{~N}, 120^{\circ} 51^{\mathrm{E}} \mathrm{E}, 14 \mathrm{~m}\right.$ in elevation), China, which has a warm-temperate climate with an average annual rainfall of $1700 \mathrm{~mm}$ spread over the year and slightly more precipitation during the winter and spring (Zheng et al. 2008a, 2014a). Animals were live-trapped in forest regions from January to December 2015. Tree sparrows were weighted as soon as possible after capture with a Sartorius balance (model BT25S, $\pm 0.1 \mathrm{~g}$ ) to determine their $M_{\mathrm{b}}$. Birds were transferred to the laboratory on the same day and placed in outdoor cages $\left(50 \times 30 \times 20 \mathrm{~cm}^{3}\right)$ for 1 or 2 days under the natural ambient temperature $\left(13 \pm 1{ }^{\circ} \mathrm{C}\right)$ and photoperiod before experiments began. Two experiments were conducted:

\section{Experiment 1}

Birds were placed in outdoor cages under the same natural conditions. The $M_{\mathrm{b}}$ and BMR of a group of captive birds were measured monthly over a year to determine seasonal changes in $M_{\mathrm{b}}$ and thermogenesis.

\section{Experiment 2}

To test the effect of temperature and photoperiod on the seasonal changes in $M_{\mathrm{b}}$ and BMR measured in Experiment 1 , twenty-four birds were randomly assigned to one of 4 treatment groups: (1) warm and long photoperiod (WL; $30^{\circ} \mathrm{C}, 16 \mathrm{~h}$ light:8 $\mathrm{h}$ dark), (2) warm and short photoperiod (WS; $30{ }^{\circ} \mathrm{C}, 8 \mathrm{~h}$ light:16 h dark), (3) cold and long photoperiod $\left(\mathrm{CL} ; 10{ }^{\circ} \mathrm{C}, 16 \mathrm{~h}\right.$ light: $8 \mathrm{~h}$ dark), and (4) cold and short photoperiod $\left(\mathrm{CS} ; 10^{\circ} \mathrm{C}, 8 \mathrm{~h}\right.$ light:16 h dark). Birds were caged individually for at least 2 weeks, after which birds were randomly assigned to one of the above treatments for 4 weeks (Swanson et al. 2014; $\mathrm{Hu}$ et al. 2017). $M_{\mathrm{b}}$ and energy budget were monitored every 7 days and BMR was measured at the end of the experiment. All experimental procedures were approved by Wenzhou University's Animal Care and Use Committee.

\section{Metabolic measurements}

Birds' metabolic rates were estimated by using an open-circuit respirometry system (S-3A/I, AEI Technologies, Pittsburgh, PA, USA) (Hu et al. 2017). The plastic metabolic measurement chambers used to measure oxygen consumption had a volume of $1.5 \mathrm{~L}$ and contained a perch for the bird to stand on (Smit and McKechnie 2010; Wang et al. 2019). The temperature of the chambers was controlled to $\pm 0.5{ }^{\circ} \mathrm{C}$ by placing them inside an incubator (BIC-300 Shanghai Boxun Medical Biological Instrument Corp., China). Air in the chamber was passed through a silica gel/soda lime/silica gel column to remove water vapor and $\mathrm{CO}_{2}$ before it was passed through the oxygen sensor (AEI technologies N-22 M, USA). A flow control system (AEI technologies R-1, USA) regulated the flow of excurrent gas to $300 \mathrm{~mL} / \mathrm{min}$ during oxygen measurements (Zheng et al. 2014a). Combined with a general purpose thermal mass flow-meter (TSI 4100 Series, USA) (McNab 2006), this kept the fractional concentration of $\mathrm{O}_{2}$ in respirometry chamber at approximately $20 \% \pm 1 \% . \mathrm{O}_{2}$ consumption was measured at $25 \pm 0.5^{\circ} \mathrm{C}$, a temperature range within the thermal neutral zone of the Eurasian Tree Sparrow (Liu and Li 2006; Zheng et al. 2008b). All gas exchange measurements were made when birds would normally be at rest (between 20:00 and 24:00) and were conducted in darkened chambers when it was reasonable to assume they were postabsorptive. Food was withheld $4 \mathrm{~h}$ before each measurement to reduce the heat increment associated with specific dynamic action (SDA) (Liu and Li 2006; Zheng et al. 2008b). Measurement of oxygen consumption began at least $1 \mathrm{~h}$ after birds were observed perching calmly, and each bird was generally kept in the chamber for at least 2 h. 5 min running means of instantaneous oxygen consumption over the entire test period were calculated using Equation two of Hill (1972) and the lowest of these was taken to be the resting metabolic rate (Smit and McKechnie 2010). All measurements were taken daily between 20:00 and 24:00.

\section{Energy budget}

Food residues and feces were collected every 3 days before treatments began (week 0 ), then weekly (every 7 days) until the end of the experiment. Food and fecal residues were separated by hand, oven-dried at $60{ }^{\circ} \mathrm{C}$ to a constant mass after which their caloric content was determined with a C2000 oxygen bomb calorimeter (IKA Instrument, Germany). Gross energy intake (GEI), Feces energy (FE), digestible energy intake (DEI) and digestibility of energy were estimated using the equations in Ni et al. (2011) and Hu et al. (2017):

$$
\text { GEI }(\mathrm{kJ} / \text { day })=\text { Dry matter intake }(\mathrm{g} / \text { day }) \times \text { Food caloric value }(\mathrm{kJ} /(\mathrm{g} \cdot \text { dry matter })) \text {. }
$$

$\mathrm{FE}(\mathrm{kJ} /$ day $)=$ Dry feces $(\mathrm{g} /$ day $) \times$ Feces caloric value $(\mathrm{kJ} /(\mathrm{g} \cdot$ dry matter $))$. 
DEI $(\mathrm{kJ} /$ day $)=$ GEI $(\mathrm{kJ} /$ day $)-$ Feces energy $(\mathrm{kJ} /$ day $)$.

Digestibility $(\%)=\operatorname{DEI}(\mathrm{kJ} /$ day $) /$ GEI $(\mathrm{kJ} /$ day $) \times 100$

\section{Measurement of organ mass}

Birds were euthanized by cervical dislocation at the end of the experiment after which the brain, heart, lungs, liver, kidneys, gizzard, small intestine, rectum and skeletal muscle of each bird were removed and weighed to the nearest $0.1 \mathrm{mg}$. Small amounts of liver and skeletal muscle tissue were taken for the preparation of mitochondria (Zheng et al. 2008b, 2010). All organs, including the remainder of the liver and skeletal muscle, were then dried at $75{ }^{\circ} \mathrm{C}$ to a constant mass over $2 \mathrm{~d}$, then weighed to the nearest $0.1 \mathrm{mg}$ to determine their dry mass (Williams and Tieleman 2000; Liu and Li 2006; Wang et al. 2019).

\section{Preparation of mitochondria}

Liver and skeletal muscle tissue for mitochondria preparation were placed in ice-cold sucrose-buffered medium, cleaned of any extraneous tissue, blotted, and weighed. Liver samples were cut into coarse pieces with scissors, then rinsed and resuspended in 5 volumes of ice-cold medium (Rasmussen et al. 2004; Zhou et al. 2016; Cui et al. 2019). Skeletal muscle samples were also cut into coarse pieces, then treated with proteinase for 5-10 $\mathrm{min}$ before resuspension in 10 volumes of ice-cold medium (Cui et al. 2019). Both the liver and skeletal muscle preparations were then homogenized in a Teflon/glass homogenizer. Each homogenate was then centrifuged at $600 \mathrm{~g}$ for $10 \mathrm{~min}$ at $4{ }^{\circ} \mathrm{C}$ in an Eppendorf centrifuge after which the pellets, comprised of nuclei and cell debris, were discarded and the supernatants centrifuged at 12,000 $\mathrm{g}$ for another $10 \mathrm{~min}$ at $4{ }^{\circ} \mathrm{C}$. The pellets obtained were suspended, re-spun at $12,000 \mathrm{~g}$, then resuspended $(2: 1, w / v$ for liver and 4:1 for skeletal muscle) in ice-cold medium (Liu and Li 2006; Zheng et al. 2008b, 2013a, b; Li et al. 2017; Cui et al. 2019). Mitochondrial protein content was estimated using the Folin phenol method, with bovine serum albumin as the standard (Lowry et al. 1951).

\section{Mitochondrial state-4 respiration (S4R) and cytochrome c oxidase activity (COX)}

S4R in liver and muscle was measured in $1.96 \mathrm{~mL}$ of respiration medium at $30{ }^{\circ} \mathrm{C}$ with a Clark electrode (Hansatech Instruments Ltd, England, DW-1). S4R was measured under substrate-dependent conditions with succinate as the substrate for $1 \mathrm{~h}$ (Zheng et al. 2008b). COX activity in liver and muscle was measured polarographically at $30^{\circ} \mathrm{C}$ using a Clark electrode at $\mathrm{pH}$ 7.2. A $10 \mathrm{~mL}$ aliquot was taken from the supernatant and $30 \mathrm{~mL}$ of cytochrome c $(37.9 \mathrm{mg} / \mathrm{mL})$ was added to the electrode, after which COX activity was measured in a final volume of $2 \mathrm{~mL}$ (Zheng et al. 2014a; Zhou et al. 2016). Mitochondrial S4R and COX activity were expressed in terms of activity in specific organs ( $\mu \mathrm{mol} \mathrm{O}_{2} /($ min'organ)) (Wiesinger et al. 1989; Zhou et al. 2016; Cui et al. 2019).

\section{Statistics}

All statistical analyses were performed in SPSS (version 21.0). Variables were first tested for normality with the Kolmogorov-Smirnov test and any that were non-normal were $\log$-transformed before being included in analyses. The statistical significance of seasonal variation in $M_{\mathrm{b}}$ and mass-specific BMR was assessed with one-way ANOVAs. The effects of temperature and photoperiod on total BMR were assessed with a two-way ANCOVA with $M_{\mathrm{b}}$ as the covariate. Repeated-measures analysis of variance (RM-ANOVA) was used to determine the significance of changes in $M_{\mathrm{b}}$, GEI, FE, DEI and digestibility, over time. Tukey's post hoc tests were used to assess the significance of differences in measurements on different days of the experiment. The significance of differences in $M_{\mathrm{b}}$, massspecific BMR and digestibility, on the same day among different groups was evaluated with a two-way ANOVA. Direct comparisons of GEI, FE and DEI on the same day among different groups were done using a two-way ANCOVA with $M_{\mathrm{b}}$ as the covariate. We used ANCOVA, with treatment (cold, warm, long photoperiod and short photoperiod) as the independent variable and log BMR as the dependent variable, and Tukey's post hoc tests for multiple comparisons among groups, to test whether BMR differed among treatment groups. The correlation between BMR and $M_{\mathrm{b}}$ necessitates removing the effect of $M_{\mathrm{b}}$ by using it as a covariate (Maldonado et al. 2009; $\mathrm{Hu}$ et al. 2017). We used $M_{\mathrm{b}}$ minus wet organ mass of the organ in question in allometric regressions of organ mass to reduce statistical problems caused by part-whole correlations (Christians 1999). When allometric correlations for organ mass were significant, we calculated residuals from the allometric equations and regressed log organ mass residuals against log BMR residuals to determine if the mass of various organs was significantly correlated with BMR. If allometric correlations were not significant, we regressed raw values for log organ mass against log BMR to test for BMR-organ mass correlations (Zheng et al. 2014a; Cui et al. 2019). Homogeneity of the slope of the dependent variable with respect to the different treatments was tested with preliminary models. Tukey's post hoc test for multiple comparisons among groups was used to assess the significance of the effects of temperature and photoperiod on mitochondrial protein and 
mitochondrial S4R and COX activity in liver and skeletal muscle. The significance of the relationships between log $\mathrm{BMR}$ and $\log M_{\mathrm{b}}$ was assessed using least-squares linear regression. Results are expressed as means \pm SEM. $P$ values $<0.05$ have been regarded as statistically significant.

\section{Results}

\section{Seasonal changes in $\boldsymbol{M}_{\mathrm{b}}$ and BMR}

The $M_{\mathrm{b}}$ of Eurasian Tree Sparrows underwent significant seasonal changes in 2015 (ANOVA, $F_{11,121}=2.009$, $P=0.033$, Fig. 1a). $M_{\mathrm{b}}$ was relatively stable from January to March $(P>0.05)$, decreased from April to August $(P<0.05$, Fig. 1a), then increased to its maximal level in December when it was $10 \%$ higher than in August. Both mass-specific and total BMR varied significantly over the seasons (ANOVA, mass-specific, $F_{11,121}=6.131$, $P<0.001$, Fig. 1b; ANCOVA, total, $F_{11,120}=5.996$, $P<0.001$, Fig. 1c). From April to December, both massspecific and total BMR increased significantly and peaked in November (mass-specific, $5.45 \pm 0.65 \mathrm{~mL} \mathrm{O} \mathrm{O}_{2} /(\mathrm{g} \cdot \mathrm{h})$; total, $\left.101.11 \pm 6.01 \mathrm{~mL} \mathrm{O}_{2} / \mathrm{h}\right)$, then declined to a minimum in April (mass-specific, $2.68 \pm 0.35 \mathrm{~mL} \mathrm{O} /(\mathrm{g} \cdot \mathrm{h}$ ); total, $50.10 \pm 7.40 \mathrm{~mL} \mathrm{O} / \mathrm{h}$ ). Mass-specific and total BMR were 51 and 50\% lower in April, respectively, than December.

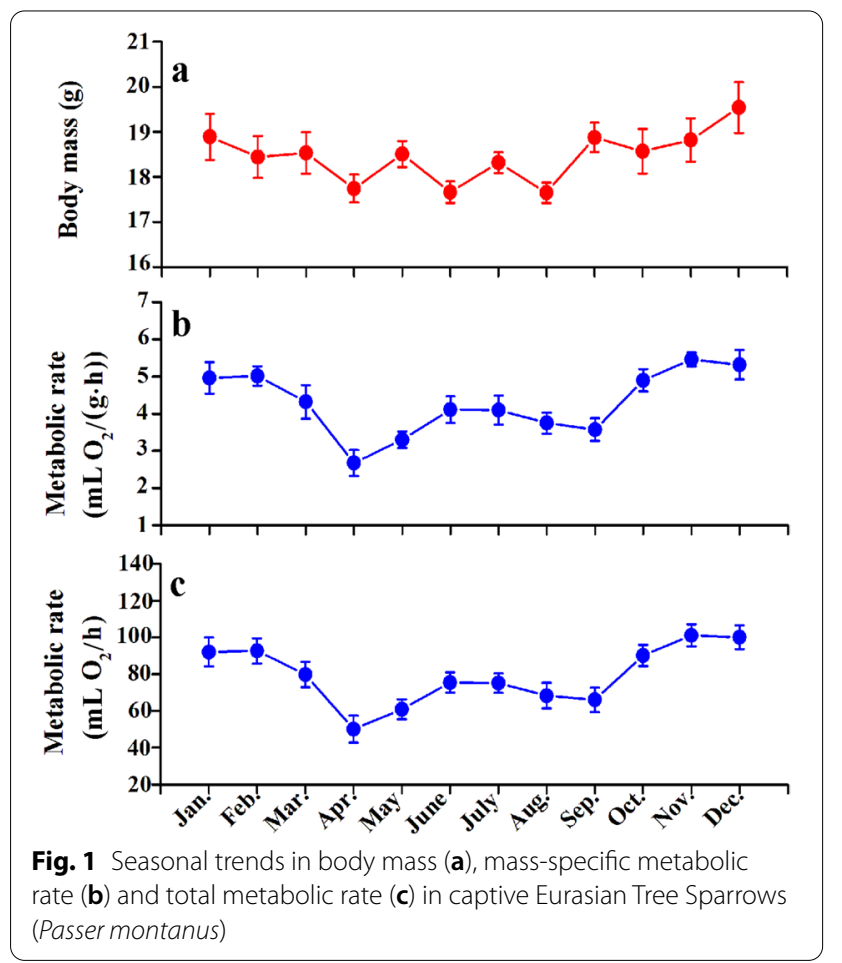

\section{Experiment 2} $M_{\mathrm{b}}$ and $B M R$

$M_{\mathrm{b}}$ did not differ significantly among the four temperature-photoperiod treatment groups at the beginning of the experimental period (Fig. 2a), nor was there a significant interaction between temperature and photoperiod (RM-ANOVA, $F_{4,80}=0.296, P=0.880$ ) during acclimation. $M_{\mathrm{b}}$ was, however, significantly affected by temperature by the end of the experiment (RM-ANOVA, $\left.F_{4,80}=13.817, P<0.001\right)$, although not by photoperiod (RM-ANOVA, $F_{4,80}=0.384, \quad P=0.819$ ). A significant decrease in $M_{\mathrm{b}}(P<0.001)$ was apparent in the warm groups after day 14 and these remained lighter than the cold groups for the entire 28 day duration of the experiment. In addition, the $M_{\mathrm{b}}$ of the warm groups was $20 \%$ lower on 28 day than that of the cold groups (Fig. 2a).

Both mass-specific $\left(\mathrm{mL} \mathrm{O}_{2} /(\mathrm{g} \cdot \mathrm{h})\right)$ and total $\left(\mathrm{mL} \mathrm{O}_{2} / \mathrm{h}\right)$ BMR were significantly affected by temperature (two-way ANOVA, mass-specific, $F_{1,20}=9.301, P=0.006$; two-way ANCOVA, total, $F_{1,19}=10.955, P=0.004$, Fig. $2 b$ ). However, photoperiod was not significantly affected by BMR (two-way ANOVA, mass-specific, $F_{1,20}=1.911, P=0.182$; two-way ANCOVA, total, $F_{1,19}=1.420, P=0.248$ ) and there was no significant interaction between temperature and photoperiod (two-way ANOVA, mass-specific, $F_{1,20}=1.417, P=0.248$; two-way ANCOVA, total, $F_{1,19}=1.740, P=0.203$, Fig. 2 b) during acclimation.

Mass-specific and total BMR in the warm groups were $17 \%$ and $31 \%$ lower, respectively, than in the cold groups. A homogeneity of slopes test indicates that the slopes of the different treatment groups are significantly different. There is a significant, positive correlation between $\log$ BMR and $\log M_{\mathrm{b}}$ in both long and short photoperiod groups (long photoperiod group, $r^{2}=0.504, P=0.010$, Fig. 2c; short photoperiod group, $r^{2}=0.529, P=0.007$, Fig. 2d).

\section{Energy budget}

GEI was significantly affected by temperature (RMANOVA, $F_{4,80}=7.205, P=0.001$ ), but not photoperiod (RM-ANOVA, $F_{4,80}=0.084, P=0.951$ ) or the interaction between temperature and photoperiod (RM-ANOVA, $F_{4,80}=0.175, P=0.884$; Fig. 3a). No between-group differences in GEI were found prior to acclimation. However, the warm groups had significantly lower GEI $(P<0.001)$ than that of the cold groups after 7 days and remained so for the 28 days duration of the experiment (Fig. 3a).

FE was not significantly affected by temperature (RMANOVA, $F_{4,80}=1.901, P=0.130$; Fig. $3 \mathrm{~b}$ ), photoperiod (RM-ANOVA, $F_{4,80}=1.258, P=0.296$ ) or the interaction between temperature and photoperiod (RM-ANOVA, $\left.F_{4,80}=1.568, P=0.200\right)$. However, ANCOVA revealed that FE was indeed affected by temperature $(P<0.001$, 


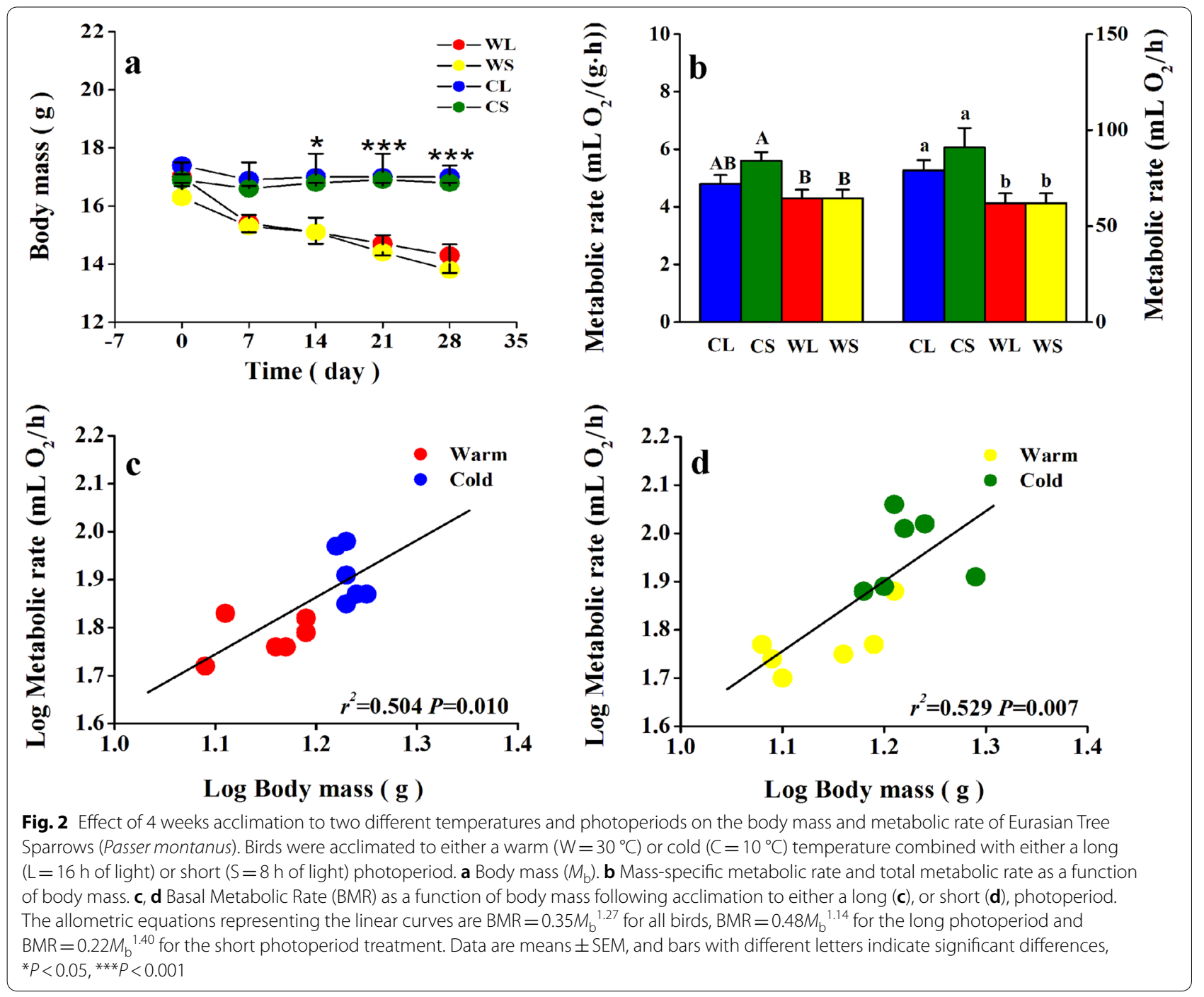

Fig. 3b). Tree sparrows acclimated to $30{ }^{\circ} \mathrm{C}$ had a significantly smaller FE than those acclimated to $10{ }^{\circ} \mathrm{C}$ (day 14 , $P=0.006$; day $21, P<0.001$; and $28, P=0.007$; Fig. $3 \mathrm{~b}$ ).

Temperature significantly affected DEI (RM-ANOVA, $F_{4,80}=5.190, P=0.004$, Fig. 3c). However, DEI was not significantly affected by photoperiod (RM-ANOVA, $\left.F_{4,80}=0.224, P=0.859\right)$ or the interaction between temperature and photoperiod (RM-ANOVA, $F_{4,80}=0.149$, $P=0.913$, Fig. 3c). The DEI of the warm groups was significantly lower $(P<0.01)$ than that of the cold groups after 7 days and remained so until the end of the experiment on 28 days (Fig. 3c).

Digestibility was significantly affected by temperature (RM-ANOVA, $F_{4,80}=3.412, P=0.013$, Fig. $3 \mathrm{~d}$ ), but not by photoperiod (RM-ANOVA, $F_{4,80}=1.308, P=0.274$ ) or the interaction between temperature and photoperiod
(RM-ANOVA, $\quad F_{4,80}=0.436, P=0.782$ ). No betweengroup differences in digestibility were found during acclimation (Fig. 3d).

\section{Organ and muscle mass}

Kidney wet mass was significantly affected by temperature (two-way ANCOVA, $F_{1,19}=9.466, P=0.006$, Table 1), and post hoc analysis showed that warm-acclimated birds had lighter kidney mass than cold-acclimated birds. The wet mass of the small intestine was also significantly affected by both temperature (two-way ANCOVA, $F_{1,19}=9.466, P=0.006$, Table 1) and photoperiod (two-way ANCOVA, $F_{1,19}=4.510, P=0.047$, Table 1). Here, the post hoc analysis revealed that warmacclimated birds had smaller small intestine than coldacclimated birds (Table 1). In contrast to the results for 

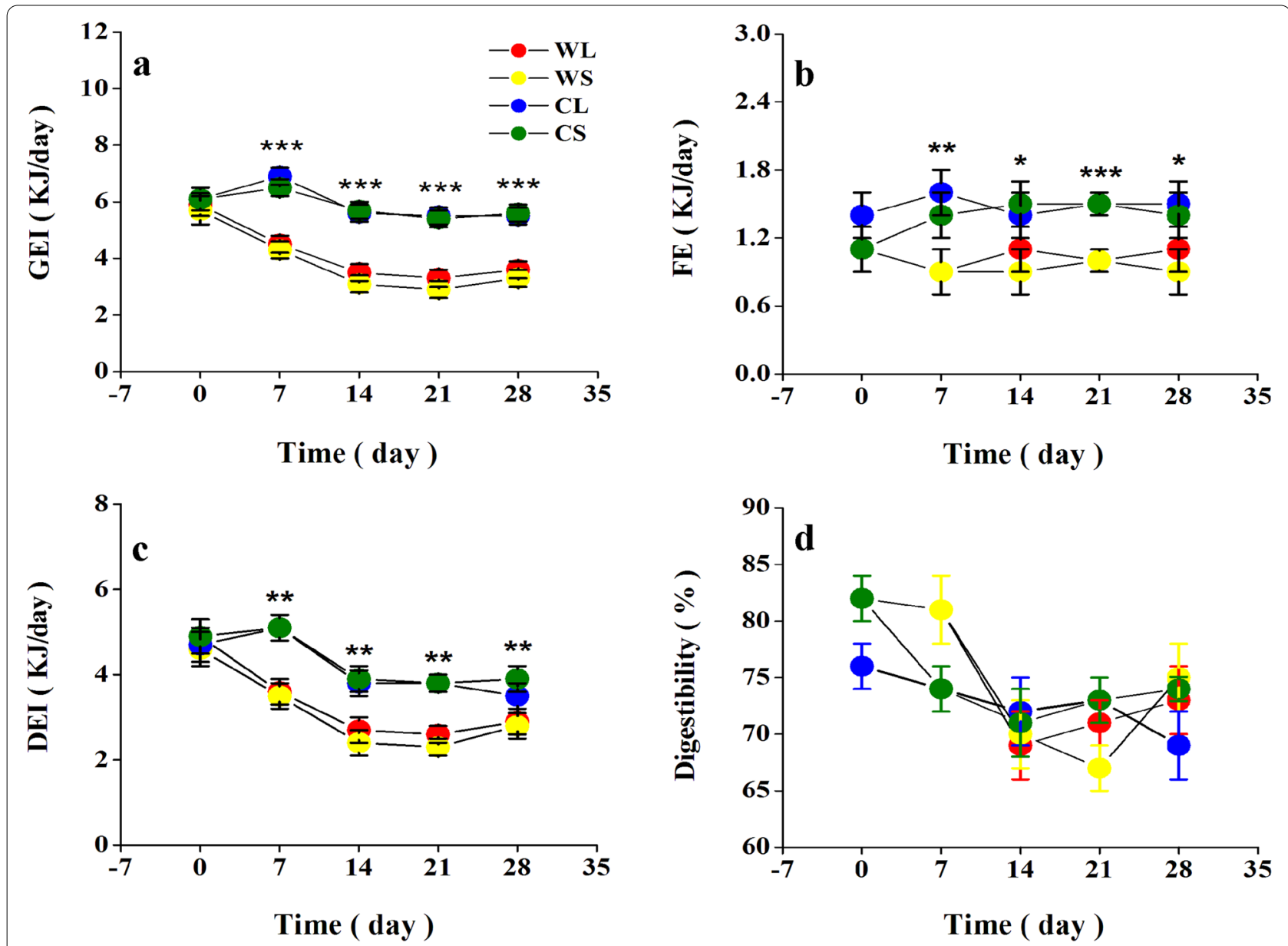

Fig. 3 Effects of acclimation to either a warm $\left(W=30^{\circ} \mathrm{C}\right)$ or cold $\left(C=10^{\circ} \mathrm{C}\right)$ temperature, and a long $(\mathrm{L}=16 \mathrm{~h}$ of light) or short $(\mathrm{S}=8 \mathrm{~h}$ of light) photoperiod, on Gross Energy Intake (GEI), Fecal Energy (FE), Daily Energy Intake (DEI) and digestibility, in the Eurasian Tree Sparrow (Passer montanus). Data are presented as mean \pm SEM. ${ }^{*} P<0.05,{ }^{* *} P<0.01,{ }^{* * *} P<0.001$ for comparisons among all four treatment groups

temperature acclimation, birds in the long photoperiod groups had a heavier small intestine than those in the short photoperiod groups (Table 1). Furthermore, the mass of the stomach, rectum and lung were affected by the interaction between temperature and photoperiod (two-way ANCOVA, stomach, $F_{1,19}=5.052, P=0.037$; rectum, $F_{1,19}=5.663, \quad P=0.028 ;$ lung, $F_{1,19}=4.683$, $P=0.043$, Table 1) during acclimation.

Liver, kidney and total digestive tract dry mass were significantly affected by temperature (two-way ANCOVA, liver, $\quad F_{1,19}=9.417, \quad P=0.006 ; \quad$ kidneys, $\quad F_{1,19}=11.913$, $P=0.003$; total digestive tract, $F_{1,19}=4.874, P=0.040$, Table 1). Post hoc analysis indicates that birds in the warm groups had a lighter liver, kidneys and total digestive tract than those in the cold groups. Rectum mass was significantly affected by the interaction between temperature and photoperiod (two-way ANCOVA, $F_{1,19}=7.760$, $P=0.012$, Table 1). Analysis of pooled data from birds indicates a positive correlation between the log dry mass of the skeletal muscle, heart, liver, kidney, small intestine, total digestive tract, and log BMR (Table 2). Regression of pooled dry organ mass and BMR data from birds vs $M_{\mathrm{b}}$, minus the wet mass of the organ concerned, were positive and significant for skeletal muscle and kidney (Table 2).

\section{Protein content, mitochondrial state-4 respiration} (S4R) and cytochrome coxidase activity (COX) in liver and muscle

By the end of the experiment, mitochondrial protein content in the liver had been significantly affected 
Table 1 Effects of temperature and photoperiod acclimation on organ mass in Eurasian Tree Sparrows

\begin{tabular}{|c|c|c|c|c|c|c|c|}
\hline \multirow{2}{*}{$\bar{B}$} & \multicolumn{2}{|c|}{ Warm acclimation $\left(30^{\circ} \mathrm{C}\right)$} & \multicolumn{2}{|c|}{ Cold acclimation $\left(10^{\circ} \mathrm{C}\right)$} & \multicolumn{3}{|c|}{ Effects } \\
\hline & Long day (16L:8D) & Short day (8L:16D) & Long day (16L:8D) & Short day (8L:16D) & $T$ & $P$ & $\mathbf{T} \times \mathbf{P}$ \\
\hline Sample size & 6 & 6 & 6 & 6 & & & \\
\hline Body mass(g) & $14.28 \pm 0.54$ & $13.80 \pm 0.54$ & $17.00 \pm 0.54$ & $16.75 \pm 0.54$ & & & \\
\hline \multicolumn{8}{|l|}{ Organ wet mass } \\
\hline Muscle (mg) & $1032.63 \pm 122.85$ & $1056.08 \pm 132.25$ & $1318.55 \pm 132.28$ & $1360.19 \pm 122.83$ & & & \\
\hline Brain (mg) & $741.12 \pm 22.95$ & $716.27 \pm 24.71$ & $701.60 \pm 24.71$ & $682.25 \pm 22.95$ & & & \\
\hline Heart (mg) & $196.11 \pm 15.73$ & $195.04 \pm 16.93$ & $222.95 \pm 16.94$ & $217.30 \pm 15.73$ & & & \\
\hline Lung (mg) & $164.71 \pm 11.15$ & $137.25 \pm 12.01$ & $123.12 \pm 12.01$ & $141.22 \pm 11.15$ & & & * \\
\hline Liver (mg) & $504.95 \pm 52.16$ & $551.41 \pm 56.16$ & $642.02 \pm 56.17$ & $622.77 \pm 52.15$ & & & \\
\hline Kidney (mg) & $128.11 \pm 8.12$ & $132.55 \pm 8.74$ & $159.91 \pm 8.74$ & $164.12 \pm 8.12$ & * & & \\
\hline Stomach (mg) & $415.91 \pm 25.22$ & $373.08 \pm 27.15$ & $355.98 \pm 27.16$ & $420.18 \pm 25.22$ & & & * \\
\hline Small intestine (mg) & $355.06 \pm 32.18$ & $298.08 \pm 34.65$ & $472.73 \pm 34.66$ & $398.15 \pm 32.18$ & $*$ & $*$ & \\
\hline Rectum (mg) & $38.47 \pm 3.83$ & $48.21 \pm 4.13$ & $54.79 \pm 4.13$ & $47.31 \pm 3.83$ & & & * \\
\hline Total digestive tract (mg) & $802.59 \pm 58.14$ & $714.88 \pm 62.60$ & $888.00 \pm 62.61$ & $935.17 \pm 58.13$ & & & \\
\hline \multicolumn{8}{|l|}{ Organ dry mass } \\
\hline Muscle (mg) & $278.33 \pm 28.76$ & $308.37 \pm 30.96$ & $341.40 \pm 30.97$ & $374.86 \pm 28.76$ & & & \\
\hline Brain (mg) & $157.30 \pm 4.26$ & $157.17 \pm 4.58$ & $155.43 \pm 4.58$ & $146.92 \pm 4.26$ & & & \\
\hline Heart (mg) & $48.23 \pm 4.54$ & $48.71 \pm 4.89$ & $55.78 \pm 4.89$ & $52.37 \pm 4.54$ & & & \\
\hline Lung (mg) & $34.79 \pm 2.26$ & $31.16 \pm 2.43$ & $26.84 \pm 2.43$ & $31.64 \pm 2.26$ & & & \\
\hline Liver (mg) & $180.87 \pm 13.77$ & $168.42 \pm 14.83$ & $224.29 \pm 14.83$ & $232.25 \pm 13.77$ & * & & \\
\hline Kidney (mg) & $33.26 \pm 2.12$ & $32.74 \pm 2.29$ & $42.59 \pm 2.28$ & $41.99 \pm 2.12$ & * & & \\
\hline Stomach (mg) & $122.51 \pm 7.25$ & $111.83 \pm 7.81$ & $114.53 \pm 7.81$ & $125.83 \pm 7.25$ & & & \\
\hline Small intestine (mg) & $101.92 \pm 10.70$ & $93.56 \pm 11.52$ & $123.65 \pm 11.53$ & $121.34 \pm 10.70$ & & & \\
\hline Rectum (mg) & $12.26 \pm 1.32$ & $15.99 \pm 1.42$ & $17.00 \pm 1.42$ & $13.81 \pm 1.32$ & & & * \\
\hline Total digestive tract (mg) & $229.44 \pm 14.04$ & $210.02 \pm 15.11$ & $266.55 \pm 15.11$ & $251.55 \pm 14.03$ & * & & \\
\hline
\end{tabular}

The statistical significance of differences between means was determined by two-way ANCOVA. Data are presented as mean \pm SEM. $T$ temperature, $P$ photoperiod, $T \times P$ the interaction between $T$ and $P ; * P<0.05$

Table 2 Allometric correlation and residual correlation for BMR versus dry organ mass (controlled for $M_{\mathrm{b}}$ minus wet organ mass) in Eurasian Tree Sparrows

\begin{tabular}{|c|c|c|c|c|c|c|c|c|c|c|}
\hline Correlation & Muscle & Brain & Heart & Lung & Liver & Kidney & Stomach & Small intestine & Rectum & Digestivetract \\
\hline \multicolumn{11}{|l|}{ Allometric } \\
\hline$R^{2}$ & 0.431 & 0.020 & 0.310 & 0.009 & 0.295 & 0.498 & 0.056 & 0.244 & 0.070 & 0.209 \\
\hline$P$ & $<0.001$ & 0.512 & 0.005 & 0.654 & 0.006 & $<0.001$ & 0.266 & 0.014 & 0.210 & 0.025 \\
\hline Slope & 0.361 & 0.443 & 0.529 & 0.137 & 0.626 & 0.653 & 0.382 & 0.429 & 0.007 & 0.671 \\
\hline \multicolumn{11}{|l|}{ Residual } \\
\hline$R^{2}$ & 0.206 & 0.000 & 0.135 & 0.050 & 0.115 & 0.223 & 0.012 & 0.035 & 0.012 & 0.051 \\
\hline$P$ & 0.026 & 0.941 & 0.078 & 0.292 & 0.105 & 0.020 & 0.615 & 0.379 & 0.604 & 0.289 \\
\hline Slope & 0.099 & -0.024 & 0.554 & -0.617 & 0.141 & 1.246 & -0.099 & 0.114 & 0.499 & 0.099 \\
\hline
\end{tabular}

by temperature (two-way ANOVA, $F_{1,20}=4.992$, $P=0.037$, Fig. 4a), but not photoperiod (two-way ANOVA, $F_{1,20}=1.953, P=0.178$, Fig. $\left.4 a\right)$ or the interaction between temperature and photoperiod (twoway ANOVA, $F_{1,20}=0.036, P=0.852$, Fig. 4a). Post hoc analysis showed that the livers of warm-acclimated birds had lower protein content than those of cold-acclimated birds. Mitochondrial S4R in the liver was also significantly affected by both temperature (two-way ANOVA, $F_{1,20}=22.516, P<0.001$, Fig. 4b) 


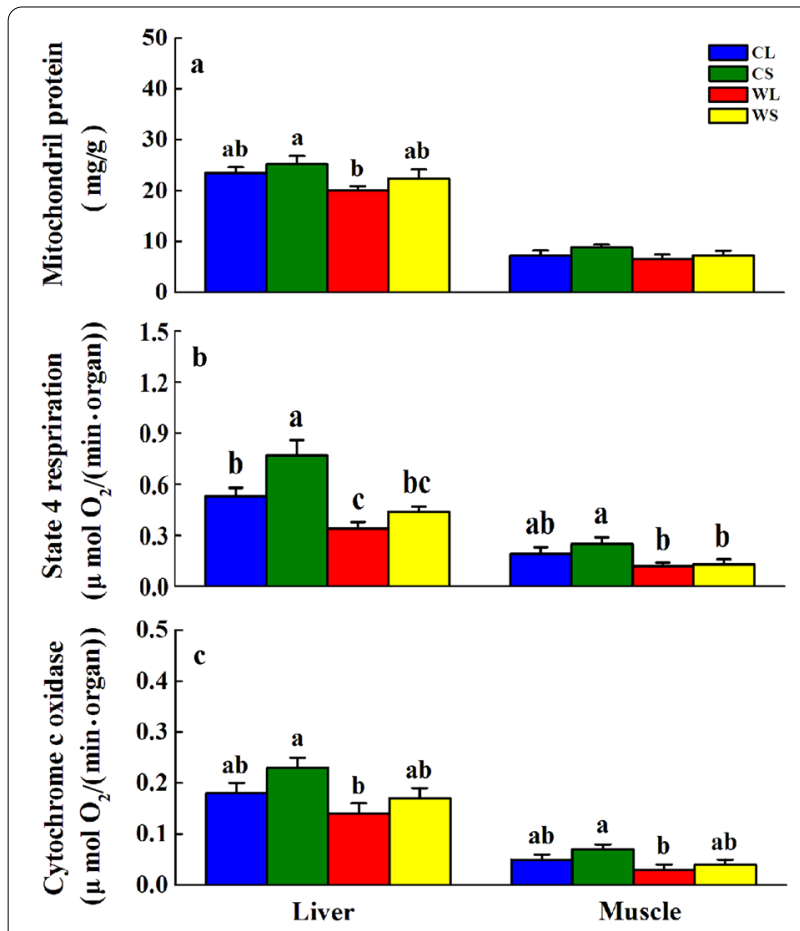

Fig. 4 Differences in mitochondrial protein (a), state-4-respiration (S4R) (b) and cytochrome c oxidase (COX) (c), activity in the liver and skeletal muscle of Eurasian Tree Sparrows (Passer montanus) acclimated to either a warm $\left(\mathrm{W}=30^{\circ} \mathrm{C}\right)$ or cold $\left(\mathrm{C}=10^{\circ} \mathrm{C}\right)$ temperature, and a long ( $\mathrm{L}=16 \mathrm{~h}$ of light) or short ( $\mathrm{S}=8 \mathrm{~h}$ of light) photoperiod, for 4 weeks. Data are means \pm SEM, and bars with different letters indicate significant differences the interaction between temperature and photoperiod (two-way ANOVA, $F_{1,20}=0.176, P=0.680$, Fig. 4a), mitochondrial S4R was significantly affected by temperature (two-way ANOVA, $F_{1,20}=8.756, P=0.008$, Fig. 4b) and post hoc analysis revealed that warmacclimated birds had lower mitochondrial S4R than cold-acclimated birds. COX activity was also significantly affected by temperature (two-way ANOVA, $F_{1,20}=5.620, P=0.028$, Fig. $4 \mathrm{c}$ ), and in this case, post hoc analysis indicated that warm-acclimated birds had lower COX activity than cold-acclimated birds.

\section{Discussion}

We found that Eurasian Tree Sparrows undergo seasonal changes in $M_{\mathrm{b}}$ and BMR, which are lower in summer and higher in winter. We also found that the $M_{\mathrm{b}}$, BMR, energy intake and organ mass of tree sparrows were lower in birds acclimated to a warm temperature $\left(30{ }^{\circ} \mathrm{C}\right)$ than in those acclimated to a cold temperature $\left(10{ }^{\circ} \mathrm{C}\right)$. Mitochondrial S4R respiration and COX activity in liver and skeletal muscle were significantly lower in birds acclimated to a warm temperature and long photoperiod. Collectively, these data suggest that the Eurasian Tree Sparrow can increase its thermogenic capacity in response to winter conditions, and provide further evidence to support the notion that small birds have high phenotypic plasticity with respect to thermogenic capacity (McKechnie et al. 2007; Liknes and Swanson 2011; Swanson et al. 2014; Hu et al. 2017).

\section{Effects of temperature and photoperiod on BMR, $M_{b}$ and energy budget}

Among the seasonal conditions encountered by animals, colder temperatures and shorter photoperiods are particularly stressful. It has been well documented that small birds and mammals can alter several aspects of their physiology, morphology, and behavior to cope with winter ambient temperatures and photoperiods (Wang et al. 1999; Swanson et al. 2014; Hu et al. 2017). Seasonal changes in metabolic thermogenesis, especially in small birds, are considered to be adaptive strategies important for survival (Liknes and Swanson 1996; Swanson and Olmstead 1999; Zheng et al. 2008b, 2014a; Li et al. 2017) and enhancement of thermogenesis in winter is common for temperate and arctic small birds (Swanson 2001; Zheng et al. 2014a). For example, Li et al. (2017) showed that the BMR of captive, winter-acclimatized Silky Starlings (Sturnus sericeus) was 33\% higher than that measured in summer. Wang et al. (2019) also found that Hwameis captured in winter had higher BMR than those captured in summer. There is also evidence that ANOVA, $F_{1,20}=0.893, P=0.356$, Fig. 4a), photop ANOVA, $F_{1,20}=0.893, P=0.356$, Fig. $\left.4 \mathrm{a}\right)$, photoperiod (two-way ANOVA, $F_{1,20}=0.850, P=0.367$, Fig. 4a) or 
warmer summer temperatures decrease BMR (Williams and Tieleman 2000; Zheng et al. 2013a). We found that captive Eurasian Tree Sparrows underwent seasonal changes in BMR, which was lowest in summer and highest in winter. Cold temperatures can cause increased surface heat loss in birds, which requires them to expend more energy to maintain a stable body temperature under such conditions. Hwameis acclimatized to $15{ }^{\circ} \mathrm{C}$ had significantly (62.4\%) higher BMR than those acclimatized to $35{ }^{\circ} \mathrm{C}$ (Zhou et al. 2016). The BMR of Hoopoe Larks acclimated to $36{ }^{\circ} \mathrm{C}$ was also $30 \%$ lower than that of those kept at $15{ }^{\circ} \mathrm{C}$ after 3 weeks (Williams and Tieleman 2000). The BMR of Laughing Doves increased when acclimated to cold temperatures but reduced when the same birds were moved to a warm room (McKechnie et al. 2007). Our results are consistent with these findings, and show that the BMR of Eurasian Tree Sparrows is lower in birds acclimated to a warm temperature than in those acclimated to a cold temperature. A short photoperiod could act independently and/or synergistically with temperature to enhance the thermogenic capacity of small birds and vice versa (Wang et al. 2016; Hu et al. 2017). However, we found that photoperiod had no significant effect on the BMR of tree sparrows over a 4 week acclimation period.

Adjustments in $M_{\mathrm{b}}$ are also major components of seasonal adaptation in animals (Zheng et al. 2008b; Wu et al. 2015; Zhao et al. 2015). Changes in $M_{\mathrm{b}}$ are an important adaptive strategy for many small birds and those inhabiting temperate environments either maintain a stable body mass, or gain mass, when exposed to winter conditions (Swanson and Merkord 2013; Zheng et al. 2008b, 2014a). The observed summer decrease of $M_{\mathrm{b}}$ in Eurasian Tree Sparrows is consistent with data collected in previous years for this population of sparrows in which $M_{\mathrm{b}}$ was also lower in summer than winter (Liu and Li 2006; Liu et al. 2008; Zheng et al. 2008b, 2014b). This pattern is similar to that reported in the sympatric Hwamei (Wu et al. 2015; Wang et al. 2019), and other temperate zone small birds (Cooper 2007; McKechnie 2008; McKechnie and Swanson 2010; Zheng et al. 2008a, 2014a; Li et al. 2017). Temperature and/or photoperiod can also cause changes in the $M_{\mathrm{b}}$ of some birds (Ni et al. 2011; Zheng et al. 2013a; Zhou et al. 2016; Hu et al. 2017; Cui et al. 2019). We found that only ambient temperature had a significant effect on the $M_{\mathrm{b}}$ of Eurasian Tree Sparrows over a 4 week acclimation period; warm acclimated birds underwent a gradual decrease in $M_{\mathrm{b}}$ whereas cold acclimated ones did not undergo any significant change in $M_{\mathrm{b}}$. The observed decrease in $M_{\mathrm{b}}$ could result from a change in energy reserves and/or thermoregulatory heat production. This decrease in $M_{\mathrm{b}}$ may also increase birds' surface to volume ratio, thereby increasing heat loss and reducing heat stress (Williams and Tieleman 2000; Zheng et al. 2013a).

The balance between energy acquisition and expenditure is critical to an animal's survival (Eikenaar et al. 2020). This balance depends on the interplay among energy intake, digestion, and the energy allocated to other functions such as thermoregulation, growth and reproduction (Wu et al. 2014a). Under cold and/or short photoperiod conditions, energy intake will increase to meet the increased energy requirements of the heat production required to maintain thermostasis (Wang et al. 1999; Goymann et al. 2006; Zhou et al. 2016; Hu et al. 2017). However, a negative energy balance can result if a decrease in energy intake reduces energy output (Zheng et al. 2013a; Wu et al. 2014b). We found that GEI, FE and DEI were significantly lower after acclimation to a warm temperature indicating that temperature affects both energy intake and energy budget. We also found that the duration of exposure to cold had a significant impact on energy expenditure, a conclusion supported by the findings of Zhou et al. (2016). We did not, however, find evidence that photoperiod or an interaction between temperature and photoperiods, had a synergistic effect on the energy budget of birds. Acclimation to a warmer ambient temperature reduced tree sparrows' energy and food requirements, but on the other hand, eating less food reduced digestive organ activity, thereby reducing heat stress.

Like previous studies, we found that tree sparrows acclimated to a warm temperature reduced their $M_{\mathrm{b}}$, BMR and energy budget whereas those acclimated to a cold temperature increased their heat production and accumulated a thick layer of insulating fat (Zheng et al. 2008b). After reducing their BMR, tree sparrows also reduce heat production to avoid heat stress. Our results suggest that the lower $M_{\mathrm{b}}$ of tree sparrows acclimated to warm temperatures may contribute to the observed decrease in BMR, as indicated by the positive correlation between these two variables. Potential mechanisms for elevating BMR in endotherms include increasing the mass of 'nutritional organs' involved in basal thermogenesis and/or increasing the aerobic enzyme capacity of these basal thermogenic organs (Starck and Rahmaan 2003; Villarin et al. 2003).

\section{Effects of temperature and photoperiod on organ mass and cellular metabolic activity in liver and muscle}

The acclimation of temperature and/or photoperiod has also been associated with changes in organ size and mass (Daan et al. 1990; Cui et al. 2019). One idea is that energetically challenged birds may adjust their food intake, and at the same time, reorganize their internal organs to improve digestive and thermal efficiency (Williams and 
Tieleman 2000; Vezina and Williams 2005; Zheng et al. 2014a). Our results show that acclimation to $30^{\circ} \mathrm{C}$ for 4 weeks led to significant decreases in the wet mass of the kidney and small intestine, and in the dry mass of the liver, kidney and small intestine. These changes in liver, kidney and small intestine mass could be adaptive regulation of organ morphology in response to changed food intake and digestion, ultimately contributing to an altered metabolic rate (Kersten and Piersma 1987; Hammond et al. 2001; Zhou et al. 2016; Hu et al. 2017). Furthermore, birds living in cold environments have been reported to increase the mass of their skeletal muscle, which has been associated with muscular shivering in small birds (Hohtola 1982; Swanson et al. 2014; Zheng et al. 2014a). We found that the skeletal muscle mass of tree sparrows was significantly correlated with BMR. The proportionately large size of locomotory muscle in birds may facilitate a significant contribution to BMR variation, despite the typically low metabolic output of this muscle at rest (Chappell et al. 1999; Zheng et al. 2014a; Zhou et al. 2016).

The liver is one of the largest and most metabolically active organs in endotherms, and consequently also has the potential to contribute to thermogenesis (Villarin et al. 2003; Zheng et al. 2014a; Hu et al. 2017). Acclimation to a cold temperature, short photoperiod or winter conditions, can increase in S4R and COX activity in the liver, which could contribute to elevated BMR (Liu et al. 2008; Zheng et al. 2008b, 2014a; Zhou et al. 2016; Hu et al. 2017; Zhang et al. 2018b; Cui et al. 2019). For example, winter-acclimatized Chinese Bulbuls increased their S4R and COX activity in the liver (Zheng et al. 2014a), which suggests that these adjustments could play an important role in winter thermogenesis (Villarin et al. 2003). In the Hwamei, cold acclimation also increased the oxidative capacity of the liver, which could also make a significant contribution to BMR (Zhou et al. 2016). In contrast, acclimation to a warm temperature, long photoperiod or summer conditions, can decrease in S4R and COX activity in the liver. Our findings are consistent with the results of a previous study on the Chinese Bulbul and the Hwamei, which found that changes in mitochondrial S4R and COX activity were correlated with changes in BMR (Bai et al. 2016; Zhou et al. 2016; Hu et al. 2017; Wang et al. 2019). In our present study, liver mitochondrial protein content, S4R, and COX activity were all significantly lower in birds acclimated to a warm temperature and/or long photoperiod compared to those acclimated to a cold temperature and/or short photoperiod, which suggests that Eurasian Tree Sparrows decrease the total respiratory capacity of the liver under warm and/or long photoperiod conditions. This finding is consistent with the results of previous research which found that seasonal acclimatization in Eurasian Tree Sparrows altered both S4R and COX activity in liver and BMR (Zheng et al. 2008b, 2014b; Zhang et al. 2018b).

Skeletal muscle has high aerobic capacity and is a primary thermogenic tissue in birds (Swanson et al. 2014; Zheng et al. 2014a; Stager et al. 2015; Cui et al. 2019). Increased thermogenic capacity could be achieved by increasing cellular metabolic intensity and/or by increasing in muscle mass. Several studies have examined the influence of tissue mass variation on individual BMR or MMR during temperature and/or seasonal acclimatization (Swanson 2010; Zheng et al. 2008b, 2014a; Zhou et al. 2016; Cui et al. 2019; Wang et al. 2019). Under cold conditions, the muscle of birds provides heat via shivering thermogenesis, which is the main component of heat production (Swanson 1991; Marjoniemi and Hohtola 1999; Vezina and Williams 2005). We found that the S4R activity of skeletal muscle mitochondria in warm acclimated sparrows was lower than that in cold acclimated birds. In addition, muscle COX activity was lower in warm-acclimated, than in cold acclimated, birds. These data suggest that modulation of muscular cellular thermogenesis is also an important aspect of temperature acclimation in the Eurasian Tree Sparrow.

\section{Conclusions}

We found that the $M_{\mathrm{b}}$ and BMR of Eurasian Tree Sparrows were lower in summer, and in birds acclimated to a warm temperature, than in winter, or in birds acclimated to a cold temperature. Our results also suggest that ambient temperature, rather than photoperiod, is the main driver of body temperature regulation and energy metabolism in the Eurasian Tree Sparrow, and that reduction in BMR is related to reduced body and organ (particularly liver and kidney) mass and energy intake. Mitochondrial respiration and COX activity in the liver and/or muscle were also significantly lower in birds acclimated to a warm temperature and long photoperiod than in those acclimated to a cold temperature and short photoperiod. These results indicate that tree sparrows reduce thermogenesis in response to a warmer ambient temperature and long photoperiod. Additional molecular evidence would improve our understanding of the complex processes associated with heat regulation in birds (Teulier et al. 2010; Stager et al. 2015). Both temperature and photoperiod affect the enzyme activity of sparrows, but temperature appears to be more important. Our results confirm the key role played by temperature in regulating thermogenesis in birds, a finding that provides a basis for future research. 


\section{Acknowledgements}

We thank Dr. Ron Moorhouse of Biological Science Editing, New Zealand for revising this manuscript. We also thank two anonymous reviewers for their helpful comments and suggestions.

\section{Authors' contributions}

$J L$ and $M L$ provided the research idea and designed the experiments. $L L, J G$, SZ, LH and XZ performed experiments; LL and JG analyzed data; LL and JG interpreted results of experiments; LL prepared Figures; $L L$ and JG drafted manuscript; LL, JG, ML and JL approved final version of manuscript; ML and $J$ edited and revised manuscript. All authors assume responsibility for the content of the paper. All authors read and approved the final manuscript.

\section{Funding}

This study was financially supported by grants from the National Natural Science Foundation of China (No. 31470472 and 31971420).

\section{Availability of data and materials}

The datasets collected in this study are archived at Wenzhou University of Life and Environmental Sciences, and are available from the corresponding author on reasonable request.

\section{Ethics approval and consent to participate}

All experimental procedures were approved by the Animal Care and Use Committee of the Wenzhou University.

\section{Consent for publication}

Not applicable.

\section{Competing interests}

No conflicts of interest, financial or otherwise, are declared by the authors.

Received: 3 July 2020 Accepted: 8 September 2020

Published online: 13 September 2020

\section{References}

Bai ML, Wu XJ, Cai KJ, Zheng WH, Liu JS. Relationships between interspecifc differences in the mass of internal organs, biochemical markers of metabolic activity, and the thermogenic properties of three small passerines. Avian Res. 2016;7:11.

Bushuev A, Tolstenkov O, Zubkova E, Solovyeva E, Kerimov A. Basal metabolic rate in free-living tropical birds: the influence of phylogenetic, behavioral, and ecological factors. Curr Zool. 2018;64:33-43.

Chappell MA, Bech C, Buttemer WA. The relationship of central and peripheral organ masses to aerobic performance variation in house sparrows. J Exp Biol. 1999;202:2269-79.

Christians JK. Controlling for body mass effects: is part-whole correlation important? Physiol Biochem Zool. 1999;72:250-3.

Cooper SJ. Daily and seasonal variation in body mass and visible fat in mountain chickadees and juniper titmice. Wilson J Ornithol. 2007;119:720-4.

Cui DQ, Wang N, Ge JR, Xu JY, Zheng WH, Liu JS. The role of temperature as a driver of metabolic flexibility in the Red-billed Leiothrix (Leiothrix lutea). Avian Res. 2019;10:46

Daan S, Masman D, Groenewold A. Avian basal metabolic rates: their association with body composition and energy expenditure in nature. Am J Physiol. 1990;259:R333-R34040.

Eikenaar C, Hegemann A, Packmor F, Kleudgen I, Isaksson C. Not just fuel: energy stores are correlated with immune function and oxidative damage in a long-distance migrant. Curr Zool. 2020;66:21-8.

Else PL, Brand MD, Turner N, Hulbert AJ. Respiration rate of hepatocytes varies with body mass in birds. J Exp Biol. 2004;207:2305-11.

Goymann W, Trappschuh M, Jensen W, Schwabl I. Low ambient temperature increases food intake and dropping production, leading to incorrect estimates of hormone metabolite concentrations in European stonechats. Horm Behav. 2006;49:644-53.

Hammond KA, Szewczak J, Król E. Efects of altitude and temperature on organ phenotypic plasticity along an altitudinal gradient. J Exp Biol. 2001:204:1991-2000.
Hill RW. Determination of oxygen consumption by use of the paramagnetic oxygen analyzer. J Appl Physiol. 1972;33:261-3.

Hohtola E. Thermal and electromyographic correlates of shivering thermogenesis in the pigeon. Comp Biochem Physiol A. 1982;73:159-66.

Hu SN, Zhu YY, Lin L, Zheng WH, Liu JS. Temperature and photoperiod as environmental cues affect body mass and thermoregulation in Chinese bulbuls (Pycnonotus sinensis). J Exp Biol. 2017;220:844-55.

Kersten M, Piersma T. High levels of energy expenditure in shorebirds; metabolic adaptations to an energetically expensive way of life. Ardea. 1987;75:175-87.

Li M, Sun YQ, Mao HZ, Xu JH, Zheng WH, Liu JS. Seasonal phenotypic flexibility in body mass, basal thermogenesis, and tissue oxidative capacity in the male Silky Starling (Sturnus sericeus). Avian Res. 2017;8:25.

Liknes ET, Swanson DL. Seasonal variation in cold tolerance, basal metabolic rate, and maximal capacity for thermogenesis in white-breasted nuthatches Sitta carolinensis and downy woodpeckers Picoides pubescens, two unrelated arboreal temperate residents. J Avian Biol. 1996;27:279-88.

Liknes ET, Swanson DL. Phenotypic flexibility in passerine birds: seasonal variation of aerobic enzyme activities in skeletal muscle. J Therm Biol. 2011:36:430-6.

Liu JS, Li M. Phenotypic flexibility of metabolic rate and organ masses among tree sparrows Passer montanus in seasonal acclimatization. Acta Zool Sin. 2006;52:469-77.

Liu JS, Li M, Shao SL. Seasonal changes in thermogenic properties of liver and muscle in tree sparrows Passer montanus. Acta Zool Sin. 2008;54:777-84.

Lowry OH, Rosebrough NJ, Farr AL, Randall RJ. Protein measurement with the Folin phenol reagent. J Biol Chem. 1951;193:265-75.

MacKinnon J, Phillipps K. A field guide to the birds of China. London: Oxford University Press; 2000.

Maldonado K, Cavieres G, Veloso C, Canals M, Sabat P. Physiological responses in rufous-collared sparrows to thermal acclimation and seasonal acclimatization. J Comp Physiol B. 2009;179:335-43.

Marjoniemi K, Hohtola E. Shivering thermogenesis in leg and breast muscles of Galliform chicks and nestlings of the domestic pigeon. Physiol Biochem Zool. 1999;72:484-92.

McKechnie AE. Phenotypic flexibility in basal metabolic rate and the changing view of avian physiological diversity: a review. J Comp Physiol B. 2008; 178:235-47.

McKechnie AE, Swanson DL. Sources and significance of variation in basal, summit and maximal metabolic rates in birds. Curr Zool. 2010;56:741-58

McKechnie AE, Chetty K, Lovegrove BG. Phenotypic flexibility in basal metabolic rate in laughing doves: responses to short-term thermal acclimation. J Exp Biol. 2007;210:97-106.

McNab BK. On the utility of uniformity in the definition of basal rate of metabolism. Physiol Zool. 1997;70:718-20.

McNab BK. The relationship among flow rate, chamber volume and calculated rate of metabolism in vertebrate respirometry. Comp Biochem Physiol $\mathrm{A}$. 2006;145:287-94.

McNab BK. Ecological factors affect the level and scaling of avian BMR. Comp Biochem Physiol A. 2009;152:22-45.

Ni XY, Lin L, Zhou FF, Wang XH, Liu JS. Effect of photoperiod on body mass, organ masses and energy metabolism in Chinese bulbul (Pycnonotus sinensis). Acta Ecol Sin. 2011;31:1703-13.

Peña-Villalobos I, Nuñez-Villegas M, Bozinovic F, Sabat P. Metabolic enzymes in seasonally acclimatized and cold acclimated rufous-collared sparrow inhabiting a Chilean Mediterranean environment. Curr Zool. 2014;60:338-50.

Piersma T, Drent J. Phenotypic flexibility and the evolution of organismal design. Trends Ecol Evol. 2003;18:228-33.

Rasmussen UF, Vielwerth SE, Rasmussen VH. Skeletal muscle bioenergetics: a comparative study of mitochondria isolated from pigeon pectoralis, rat soleus, rat biceps brachii, pig biceps femoris and human quadriceps. Comp Biochem Physiol A. 2004;137:435-46.

Saarela S, Heldmaier G. Effect of photoperiod and melatonin on cold resistance, thermoregulation and shivering/nonshivering thermogenesis in Japanese quail. J Comp Physiol B. 1987;157:625-33.

Sandoval L, David RW. Local predation pressure predicts the strength of mobbing responses in tropical birds. Curr Zool. 2012;58:781-90. 
Smit B, McKechnie AE. Avian seasonal metabolic variation in a subtropical desert: basal metabolic rates are lower in winter than in summer. Funct Ecol. 2010;24:330-9.

Starck JM, Rahmaan GHA. Phenotypic flexibility of structure and function of the digestive system of Japanese quail. J Exp Biol. 2003;206:1887-97.

Stager M, Swanson DL, Heviron ZA. Regulatory mechanisms of metabolic fexibility in the dark-eyed junco (Junco hyemalis). J Exp Biol. 2015;218:767-77.

Swanson DL. Seasonal variation in cold hardiness and peak rates of coldinduced thermogenesis in the dark-eyed junco Junco hyemalis. Auk. 1990;107:561-6.

Swanson DL. Substrate metabolism under cold stress in seasonally acclimatized dark-eyed juncos. Physiol Biochem Zool. 1991;64:1578-92.

Swanson DL. Are summit metabolism and thermogenic endurance correlated in winter acclimatized passerine birds? J Comp Physiol B. 2001;171:475-81.

Swanson DL. Seasonal metabolic variation in birds: functional and mechanistic correlates. In: Thompson CF, editor. Current ornithology. Berlin: Springer; 2010. p. 75-129.

Swanson DL, Olmstead KL. Evidence for a proximate influence of winter temperature on metabolism in passerine birds. Physiol Biochem Zool. 1999;72:566-75.

Swanson DL, Merkord CL. Seasonal phenotypic flexibility of flight muscle size in small birds: a comparison of ultrasonography and tissue mass measurements. J Ornithol. 2013;154:119-27.

Swanson DL, Zhang YF, Liu JS, Merkord CL, King MO. Relative roles of temperature and photoperiod as drivers of metabolic flexibility in dark-eyed juncos. J Exp Biol. 2014;217:866-75.

Swanson D, McKechnie AE, Vézina F. How low can you go? An adaptive energetic framework for interpreting basal metabolic rate variation in endotherms. J Comp Physiol B. 2017;187:1039-56.

Teulier L, Rouanet JL, Letexier D, Romestaing C, Belouze M, Rey B, et al. Coldacclimation-induced non-shivering thermogenesis in birds is associated with upregulation of avian UCP but not with innate uncoupling or altered ATP efficiency. J Exp Biol. 2010;213:2476-82.

Vézina F, Williams TD. Interaction between organ mass and citrate synthase activity as an indicator of tissue maximal oxidative capacity in breeding European starlings: implications for metabolic rate and organ mass relationships. Funct Ecol. 2005;19:119-28.

Villarin JJ, Schaeffer PJ, Markle RA, Lindstedt SL. Chronic cold exposure increases liver oxidative capacity in the marsupial. Comp Biochem Physiol A. 2003;136:621-30.

Wang DH, Sun RY, Wang ZW, Liu JS. Effects of temperature and photoperiod on thermogenesis in plateau pikas (Ochotona curzoniae) and root voles (Microtus oeconomus). J Comp Physiol B. 1999;169:77-83.

Wang JQ, Wang JJ, Wu XJ, Zheng WH, Liu JS. Short photoperiod increases energy intake, metabolic thermogenesis and organ mass in silky starlings Sturnus sericeus. Zool Res. 2016;37:75-83.

Wang Y, Shan SS, Zhang HD, Dong BB, Zheng WH, Liu JS. Physiological and biochemical thermoregulatory responses in male Chinese Hwameis to seasonal acclimatization: phenotypic flexibility in a small passerine. Zool Stud. 2019;58:6

Wiesinger $\mathrm{H}$, Heldmaier $\mathrm{G}$, Buchberger A. Effect of photoperiod and acclimation temperature on nonshivering thermogenesis and GDP-binding of brown fat mitochondria in the Djungarian hamster Phodopus s. sungorus. Pflügers Arch. 1989;413:667-72.

Williams JB, Tieleman BI. Flexibility in basal metabolic rate and evaporative water loss among hoopoe larks exposed to different environmental temperatures. J Exp Biol. 2000;203:3153-9.

Wu MS, Xiao YC, Fang Y, Zhou LM, Zheng WH, Liu JS. Seasonal variation in body mass and energy budget in Chinese bulbuls (Pycnonotus sinensis). Avian Res. 2014a;5:4.

Wu MX, Zhou LM, Zhao LD, Zhao ZJ, Zheng WH, Liu JS. Seasonal variation in body mass, body temperature and thermogenesis in the Hwamei Garrulax canorus. Comp Biochem Physiol A. 2015;179:113-9.
Wu YN, Lin L, Xiao YC, Zhou LM, Wu MS, Zhang HY, et al. Effects of temperature acclimation on body mass and energy budget in the Chinese bulbul Pycnonotus sinensis. Zool Res. 2014b;35:33-41.

Zhang YF, Eyster K, Swanson DL. Context-dependent regulation of pectoralis myostatin and lipid transporters by temperature and photoperiod in dark-eyed juncos. Curr Zool. 2018a;64:23-31.

Zhang YY, Yang K, Yang PP, Su YS, Zheng WH, Liu JS. Food restriction decreases BMR, body and organ mass, and cellular energetics, in the Chinese Bulbul (Pycnonotus sinensis). Avian Res. 2018b;9:39.

Zhao LD, Wang RM, Wu YN, Wu MS, Zheng WH, Liu JS. Daily variation in body mass and thermoregulation in male hwamei Garrulax canorus at different seasons. Avian Res. 2015;6:4

Zheng WH, Liu JS, Jang XH, Fang YY, Zhang GK. Seasonal variation on metabolism and thermoregulation in Chinese bulbul. J Therm Biol. 2008a;33:315-9.

Zheng WH, Li M, Liu JS, Shao SL. Seasonal acclimatization of metabolism in Eurasian tree sparrows (Passer montanus). Comp Biochem Physiol A 2008b;151:519-25.

Zheng WH, Fang YY, Jang XH, Zhang GK, Liu JS. Comparison of thermogenic character of liver and muscle in Chinese bulbul Pycnonotus sinensis between summer and winter. Zool Res. 2010;31:319-27.

Zheng WH, Lin L, Liu JS, Pan H, Cao MT, Hu YL. Physiological and biochemical thermoregulatory responses of Chinese bulbuls Pycnonotus sinensis to warm temperature: Phenotypic flexibility in a small passerine. J Therm Biol. 2013a;38:240-6.

Zheng WH, Lin L, Liu JS, Xu XJ, Li M. Geographic variation in basal thermogenesis in little buntings: Relationship to cellular thermogenesis and thyroid hormone concentrations. Comp Biochem Physiol A. 2013b;164:483-90.

Zheng WH, Liu JS, Swanson DL. Seasonal phenotypic flexibility of body mass, organ masses, and tissue oxidative capacity and their relationship to RMR in Chinese bulbuls Pycnonotus sinensis. Physiol Biochem Zool. 2014a;87:432-44

Zheng WH, Li M, Liu JS, Shao SL, Xu XJ. Seasonal variation of metabolic thermogenesis in Eurasian tree sparrows (Passer montanus) over a latitudinal gradient. Physiol Biochem Zool. 2014b;87:704-18.

Zhou LM, Xia SS, Chen Q, Wang RM, Zheng WH, Liu JS. Phenotypic flexibility of thermogenesis in the Hwamei (Garrulax canorus): responses to cold acclimation. Am J Physiol. 2016;310:R330-R33636.

Ready to submit your research? Choose BMC and benefit from

- fast, convenient online submission

- thorough peer review by experienced researchers in your field

- rapid publication on acceptance

- support for research data, including large and complex data types

- gold Open Access which fosters wider collaboration and increased citations

- maximum visibility for your research: over 100M website views per year

At BMC, research is always in progress.

Learn more biomedcentral.com/submissions 